\title{
Albumin excretion rate levels in non-diabetic offspring of NIDDM patients with and without nephropathy
}

\author{
G. Gruden, P. Cavallo-Perin, C. Olivetti, E. Repetti, R. Sivieri, A. Bruno, G. Pagano \\ ${ }^{1}$ Institute of Internal Medicine, University of Turin, Turin, Italy \\ ${ }^{2}$ Department of Medicine, "E. Agnelli" Hospital, Pinerolo, Italy
}

\begin{abstract}
Summary Familial clustering of diabetic nephropathy points to genetic susceptibility. The observation that in non-diabetic subjects microalbuminuria occurs more frequently in the presence of a parental history of diabetes supports this hypothesis. However, the role of inherited factors is poorly understood in noninsulin dependent diabetes mellitus (NIDDM). This study investigated the albumin excretion rate in nondiabetic offspring of NIDDM patients with increased albumin excretion rate $(>20 \mu \mathrm{g} / \mathrm{min})$ or normal albumin excretion rate $(<20 \mu \mathrm{g} / \mathrm{min})$. We recruited 20 offspring of NIDDM patients with increased albumin excretion rate (A-off) and 20 offspring of NIDDM patients with normal albumin excretion rate ( $\mathrm{N}$-off), matched for age, sex, body mass index, blood pressure and estimated protein intake.
\end{abstract}

All offspring were normotensive, had normal creatinine clearance, normal glucose tolerance and sterile urine collection. Albumin excretion rate was measured on three sterile overnight urine collections and median values were used for calculations. Albumin excretion rate was significantly higher in A-off than in $\mathrm{N}$-off $(7.7 \pm 1.2 \mathrm{vs} 3.4 \pm 0.6 \mu \mathrm{g} / \mathrm{min} p<0.01)$ and significantly related to parents' albumin excretion rate $(p<0.01, r=0.53)$. These results suggest that an increased glomerular permeability is present in nondiabetic offspring of NIDDM patients with increased albumin excretion rate. [Diabetologia (1995) 38: 1218-1222]

Key words Non-insulin-dependent diabetes mellitus, albumin excretion rate, offspring.
Microalbuminuria (albumin excretion rate, [AER] $20-200 \mu \mathrm{g} / \mathrm{min}$ ) has been shown to predict both early cardiovascular mortality [1-3] and progression to renal disease [1] in diabetic patients. Only a subset of insulin-dependent diabetic patients are at risk of developing nephropathy [4] and the clustering in families suggests a genetic susceptibility [4]. This predisposition seems to be inherited independently of dia-

Received: 11 November 1994 and in revised form: 28 March 1995

Corresponding author: Dr. P. Cavallo-Perin, Institute of Internal Medicine, Corso Dogliotti, 14, I-10126 Turin, Italy

Abbreviations: NIDDM, Non-insulin-dependent diabetes mellitus; AER, albumin excretion rate; OGTT, oral glucose tolerance test; A-off, offspring of NIDDM patients with increased albumin excretion rate; $\mathrm{N}$-off, offspring of NIDDM patients without increased albumin excretion rate. betes mellitus, but is expressed only in those patients who develop the disease [5].

It has been hypothesized that the risk of diabetic nephropathy is associated with a genetic predisposition to hypertension in patients with insulin-dependent diabetes $[6,7]$, but this issue is less clear in noninsulin-dependent diabetic (NIDDM) patients. In fact, prediabetic blood pressure predicts abnormal AER after the onset of diabetes in Pima Indians [7], but the increased risk of diabetic nephropathy in the offspring remains even after being adjusted for blood pressure [8].

In the general population, microalbuminuria is associated with impaired glucose tolerance [9], hyperinsulinaemia, hypertension, and dyslipidaemia [10], and has been proposed as a feature of the insulin resistance syndrome (syndrome X) $[10,11]$. This syndrome is typical of the diabetic and prediabetic state [12], as well of a parental history of diabetes [13], sug- 


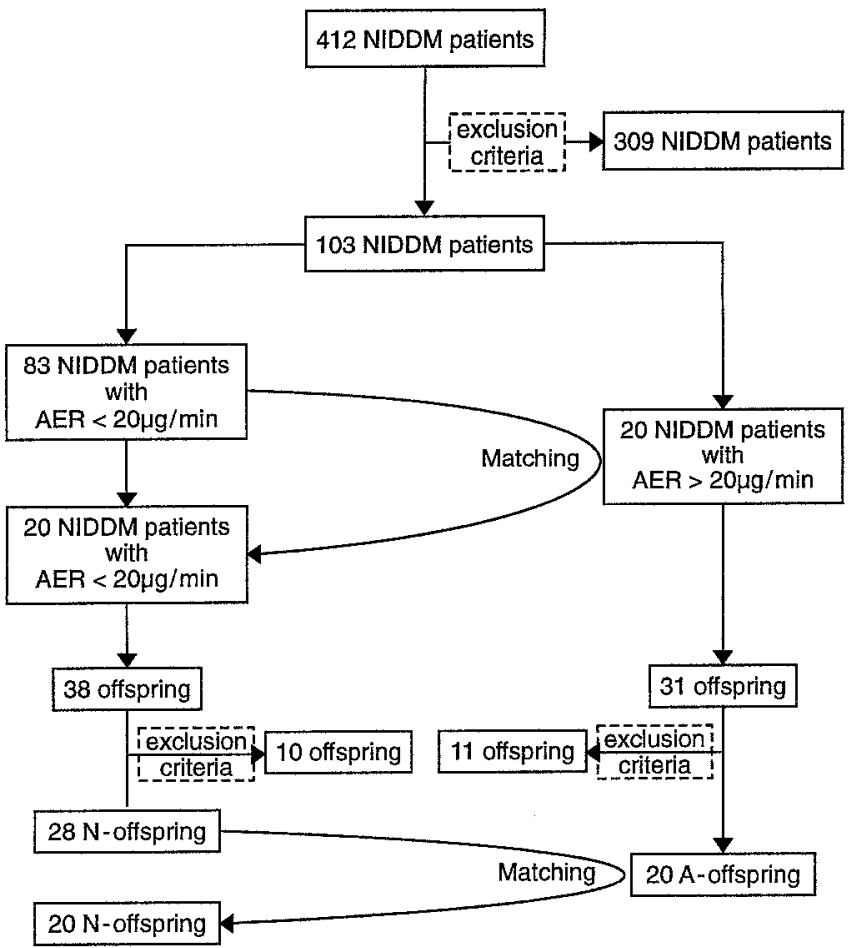

Fig. 1. Selection of patients and offspring

gesting that renal abnormalities may not only precede the onset of diabetes, but also be present in offspring of NIDDM patients. The Mexico City Diabetes Study [11], in which microalbuminuria was more frequent in non-diabetic subjects with a parental history of diabetes, supports this hypothesis.

The present study looked for the presence of increased glomerular permeability in non-diabetic offspring of NIDDM patients with increased AER by measuring their AER and other haemodynamic and metabolic parameters.

\section{Subjects and methods}

To avoid the bias of confounding factors influencing AER, we selected for the study two groups of parents and offspring matched for age, sex, body mass index (BMI), blood pressure, smoking habit, and estimated protein intake. Patients with urinary tract infections, acute diseases, and non-diabetic renal diseases were excluded (evaluation was based on clinical assessment and standard diagnostic procedures). All NIDDM patients taking drugs other than antidiabetic and antihypertensive agents and those aged 80 years or more were also excluded.

Details of patients and offspring selection are represented in Figure 1. Among 412 NIDDM patients attending our diabetic clinic, 103 had offspring and fullfilled the inclusion criteria. Of these patients $20(19.4 \%$ ) had AER above $20 \mu \mathrm{g} / \mathrm{min}$ and $83(80.6 \%)$ were normoalbuminuric. A comparable group of normoalbuminuric patients was created by matching each patient with AER above $20 \mu \mathrm{g} / \mathrm{min}$ with a normoalbuminuric patient with similar characteristics (Table 1). Inclusion criteria for offspring were: age over 18 years, normal glucose tolerance and normal creatinine clearance. From 31 offspring of NIDDM patients with AER above $20 \mu \mathrm{g} / \mathrm{min}$ (A-
Table 1. Clinical and metabolic characteristics of the parents

\begin{tabular}{lcc}
\hline & \multicolumn{2}{c}{ NIDDM patients } \\
\cline { 2 - 3 } & Increased AER & Normal AER \\
\hline$n$ & 20 & 20 \\
Age (years) & $62 \pm 2$ & $62 \pm 1$ \\
Sex (male/female) & $11 / 9$ & $9 / 11$ \\
Smokers (yes/no) & $4 / 16$ & $4 / 16$ \\
BMI (kg/m $)^{\mathrm{a}}$ & $27(21-36)$ & $26.5(22-35)$ \\
Diabetes duration (years) & $17 \pm 2$ & $16 \pm 1$ \\
HbA $1 \mathrm{c}$ (\%) & $8.7 \pm 0.5$ & $8.0 \pm 0.4$ \\
Systolic BP (mmHg) & $150(124-210)$ & $140(120-165)$ \\
Diastolic BP (mmHg) & $90(76-120)$ & $83.5(60-100)$ \\
Antihypertensive & & \\
Treatment (yes/no) & $16 / 4$ & $16 / 4$ \\
Serum creatinine $(\mu \mathrm{mol} / \mathrm{l})$ & $88.4 \pm 8.8$ & $79.6 \pm 0.8$ \\
AER ( $\mu$ g/min) & $141.3(25-763)$ & $9.46(0.5-12)$ \\
\hline
\end{tabular}

Results are means \pm SEM; ${ }^{\text {a }}$ Parameters with a skewed distribution are median (range); BP, Blood pressure

Table 2. Clinical and metabolic characteristics of the offspring of diabetic parents

\begin{tabular}{|c|c|c|}
\hline & \multicolumn{2}{|l|}{ Offspring } \\
\hline & $\begin{array}{l}\text { without } \\
\text { nephropathy }\end{array}$ & $\begin{array}{l}\text { with } \\
\text { nephropathy }\end{array}$ \\
\hline$n$ & 20 & 20 \\
\hline Age (years) & $31 \pm 1$ & $30 \pm 2$ \\
\hline Sex (male/female) & $8 / 12$ & $12 / 8$ \\
\hline Smokers (yes/no) & $5 / 15$ & $4 / 16$ \\
\hline $\mathrm{BMI}\left(\mathrm{kg} / \mathrm{m}^{2}\right)^{\mathrm{a}}$ & $22.5(18-32)$ & $23(18-36)$ \\
\hline $\mathrm{HbA}_{1 \mathrm{c}}(\%)$ & $5.5 \pm 0.1$ & $5.2 \pm 0.1$ \\
\hline Systolic BP (mmHg) & $120(95-140)$ & $122(100-132)$ \\
\hline Diastolic BP (mmHg) & $78(55-90)$ & $76(61-90)$ \\
\hline $\begin{array}{l}\text { Creatinine clearance } \\
(\mathrm{ml} / \mathrm{s})\end{array}$ & $1.65 \pm 0.1$ & $1.71 \pm 0.09$ \\
\hline $\begin{array}{l}\text { Estimated protein } \\
\text { intake }(\mathrm{g} / 24 \mathrm{~h})\end{array}$ & $95.4 \pm 5.9$ & $83.9 \pm 4.4$ \\
\hline Triglycerides $(\mathrm{mmol} / \mathrm{l})^{\mathrm{a}}$ & $1.06(0.39-2.82)$ & $0.78(0.32-3.97)$ \\
\hline $\begin{array}{l}\text { Total cholesterol } \\
(\mathrm{mmol} / \mathrm{l})\end{array}$ & $4.50 \pm 0.17$ & $4.54 \pm 0.21$ \\
\hline $\begin{array}{l}\text { HDL-cholesterol } \\
(\mathrm{mmol} / \mathrm{l})\end{array}$ & $1.37 \pm 0.08$ & $1.25 \pm 0.04$ \\
\hline $\begin{array}{l}\text { LDL-cholesterol } \\
(\mathrm{mmol} / \mathrm{l})\end{array}$ & $3.14 \pm 0.15$ & $2.82 \pm 0.19$ \\
\hline
\end{tabular}

Results are means \pm SEM; ${ }^{a}$ Parameters with a skewed distribution are median (range); BP, Blood pressure

off), 11 were excluded ( 1 had NIDDM, 3 impaired glucose tolerance, 3 hypertension, 4 undergoing drug treatments). From 38 offspring of normoalbuminuric patients ( $\mathrm{N}$-off), 11 were excluded ( 5 had impaired glucose tolerance, 2 hypertension, and 3 undergoing drug treatments). A comparable group of $\mathrm{N}$-off was created by matching each A-off subject with a normoalbuminuric subject of similar characteristics (Table 2). 

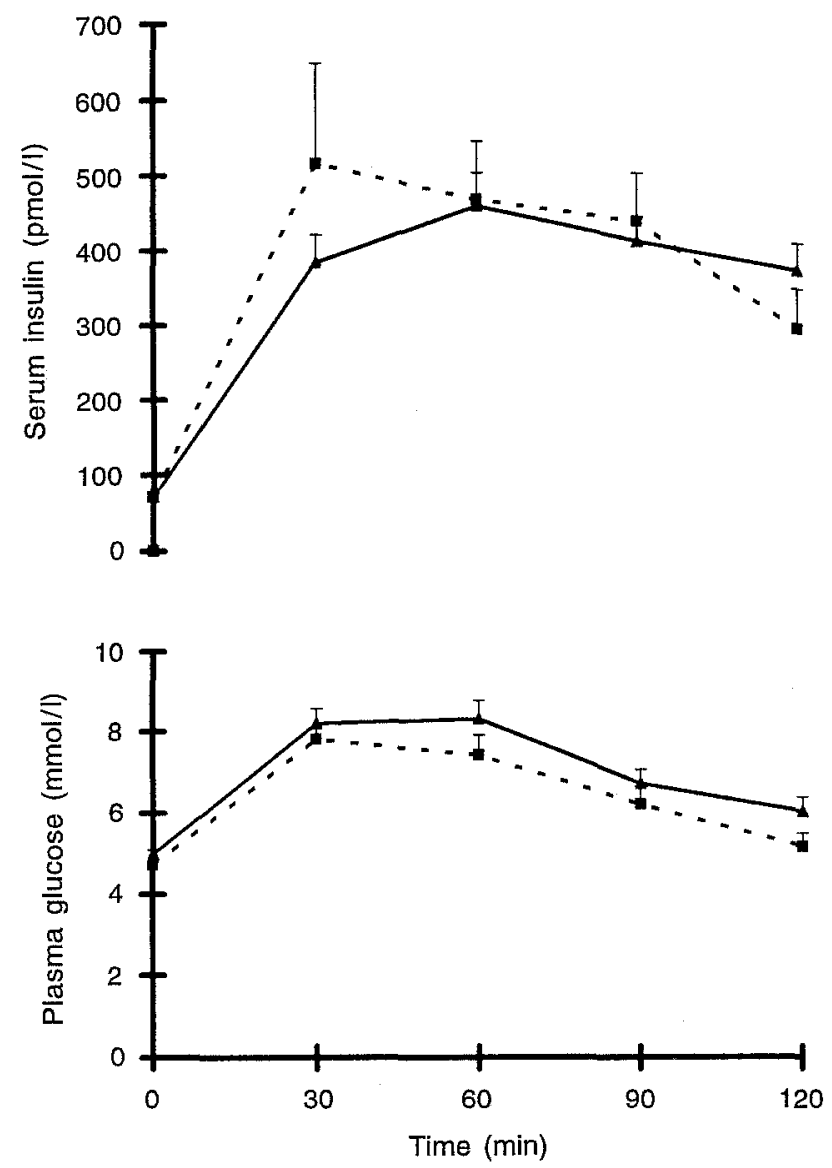

Fig.2. Plasma glucose and serum insulin values during OGTT ( $\triangle--\triangle \mathrm{N}$-offspring; $\square---\square$ A-offspring) (mean \pm SEM)

All the procedures followed were in accord with Helsinki Declaration of 1975. Informed consent was obtained from all subjects.

Diabetes was diagnosed and an oral glucose tolerance test (OGTT) evaluated according to World Health Organization (WHO) criteria [14]. Patients were considered macroalbuminuric if AER was above $200 \mu \mathrm{g} / \mathrm{min}$, microalbuminuric if AER was $20-200 \mu \mathrm{g} / \mathrm{min}$, and normoalbuminuric if AER was less than $20 \mu \mathrm{g} / \mathrm{min}$ in two of three overnight urine collections. Blood pressure was measured three times on the right arm with a standard sphygmomanometer and the mean value used for comparison. Hypertension was defined according to the WHO criteria [15] or if the patient was undergoing anti-hypertensive treatment. Daily protein intake was estimated on the basis of 24-h urinary excretion of urea nitrogen and non-urea nitrogen [16].

Fasting blood samples were obtained for plasma glucose, serum insulin, $\mathrm{HbA}_{1 \mathrm{c}}$, serum creatinine, and plasma lipid determinations. A 75-g OGTT was performed in all offspring at 08.00 hours in the morning and blood samples were drawn every $30 \mathrm{~min}$ for $120 \mathrm{~min}$ after glucose ingestion for plasma glucose and serum insulin determinations.

Plasma glucose was assayed by the glucose oxidase method (Beckmann II Glucose Analyzer, Fullerton, Calif., USA) and serum insulin by radioimmunoassay (solid-phase antibody radioimmunoassay, Kornig Kit; Metfield, Mass., USA). Areas under glucose and insulin curves during OGTT were calculated, and expressed as concentrations over time. Creatinine concentration was measured using the colorimetric method (picric acid) method of Jaffe. Triglycerides and total choles-
G. Gruden et al:: Albumin excretion rate in non-diabetic offspring

terol were measured enzymatically (Boehringer Mannheim, Mannheim, Germany), and HDL-cholesterol by precipitation with heparin and $\mathrm{MgCl}_{2}$ on whole plasma. LDL-cholesterol was calculated by Friedewald's formula [17].

AER was assessed on three sterile overnight urine collections. Urinary albumin concentration was measured by radioimmunoassay (Kabi-Pharmacia AB, Uppsala, Sweden); interand intra-assay coefficients of variation were 7.8 and $4.2 \%$, respectively. AER was calculated as the timed urine volume multiplied by the albumin concentration. The median value calculated on the three urine collections was used as individual value.

\section{Statistical analysis}

Results are expressed as means \pm SEM. Student's $t$-test for unpaired data and linear correlation was used for statistical analysis when values were normally distributed, otherwise the Rank Sum test and Spearman's test were employed. Variance analysis for repeated measured was used to compare glucose and insulin values during the OGTT. AER in offspring was taken as the dependent variable and the other parameters as independent variables in stepwise multiple regression analysis, which was performed on both groups of offspring and parents and in each group separately. For regression analysis, AER, triglycerides, diastolic blood pressure were converted to log values because of their skewed distribution. The threshold of statistical significance was taken as $p<0.05$. All statistical analyses were performed with SAS software [18].

\section{Results}

Clinical and metabolic characteristics of the diabetic patients and their offspring are reported in Tables 1 and 2 , respectively. There was no significant difference in the two offspring groups for metabolic and haemodynamic variables (Table 2 and Fig. 2). In particular, glucose and insulin values were similar, both fasting and during OGTT (Fig. 2) or calculated as areas under the curves (plasma glucose: $4.98 \pm 0.10$ vs $4.72 \pm 0.13 \mathrm{mmol} / \mathrm{l} ;$ serum insulin $71.03 \pm 5.02 \mathrm{vs}$ $71.03 \pm 6.45 \mathrm{pmol} / \mathrm{l})$. AER was significantly higher in A-off than in N-off: $7.7 \pm 1.2$ vs $3.4 \pm 0.6 \mu \mathrm{g} / \mathrm{min}$, Fig. 3).

In addition, there was a significant positive correlation between offspring AER and parents AER in all subjects as a whole $(p<0.01, r=0.53)$ and in microalbuminuric parents - A-offspring group $(p<0.002, r=0.64)$, but not in normoalbuminuric parents - N-offspring group. The factors significant on univariate analysis with offspring AER were parents' AER $(p<0.0009, r=0.50)$ and HDL-cholesterol ( $p<0.003, r=-0.34)$. In stepwise multiple regression analysis, the best model to explain the variance of the dependent variable "offspring AER" included parents' AER and offspring systolic blood pressure both when all subjects were considered as a whole and in the microalbuminuric parents - A-offspring group (Table 3 ). 


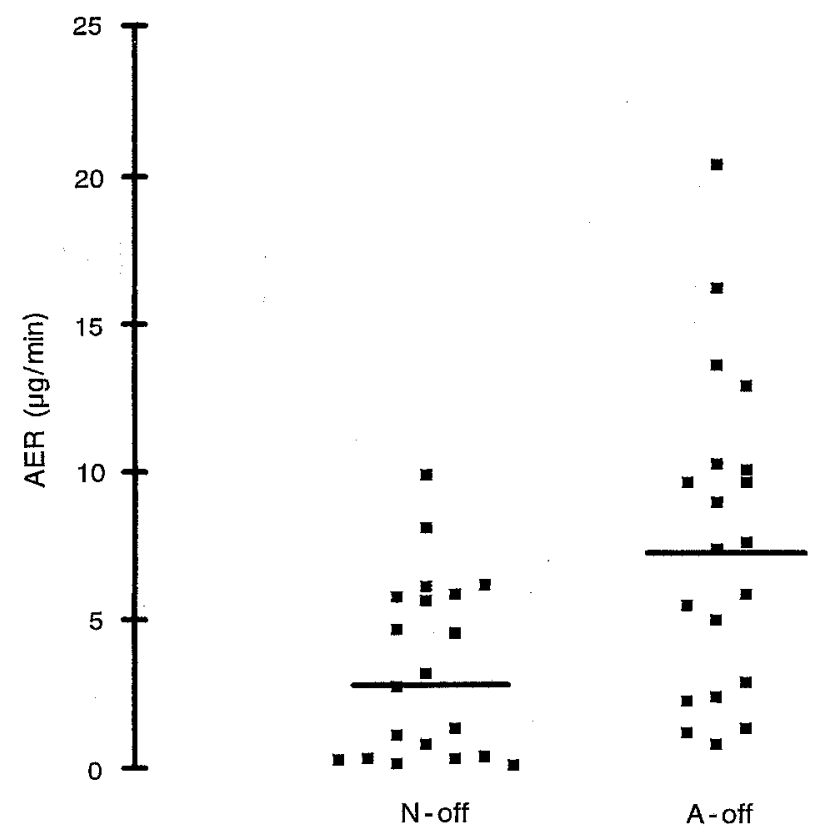

Fig.3. Individual (square) and mean (horizontal bar) values of AER in 20 offspring of NIDDM patients with nephropathy (A-off) and 20 offspring of NIDDM patients without nephropathy (N-off). Rank sum $p<0.01$

Table 3. Stepwise multiple regression analysis

\begin{tabular}{lll}
\hline & \multicolumn{2}{l}{ LOG-AER in offspring } \\
\cline { 2 - 3 } & $\begin{array}{l}\text { Partial } \\
\left(r^{2}\right)\end{array}$ & $\begin{array}{l}\text { Model } \\
\left(r^{2}\right)\end{array}$ \\
\hline LOG-AER in parents & 0.25 & $0.25^{\mathrm{a}}$ \\
Systolic blood pressure & 0.05 & 0.30 \\
\hline LOG-AER in parents & LOG-AER in A-offspring \\
\hline Systolic blood pressure & 0.24 & $0.24^{\mathrm{b}}$ \\
\hline
\end{tabular}

Significance level of model 0.15 . ${ }^{\mathrm{a}} p=0.0009 ;{ }^{\mathrm{b}} p=0.001$

\section{Discussion}

Albumin excretion rate was significantly higher in Aoff than in N-off, suggesting increased glomerular permeability and/or increased intraglomerular pressure in non-diabetic offspring of NIDDM patients with increased AER. The validity of this conclusion depends on how far the influence of possible confounding factors can be reasonably excluded.

Non-diabetic renal disease has been found at renal biopsy in up to $30 \%$ of NIDDM patients with increased AER [19]. Since the majority of our patients did not give their informed consent for renal biopsy, patients and offspring were selected for non-diabetic renal disease on clinical grounds and through non-invasive procedures. In particular, subjects with urinary tract infections, haematuria, cellular casts on sediment, altered shape or renal dimension, or any clinical or laboratory evidence of renal disease, as well as renal involvement of multisystemic disease, were excluded. In addition, we selected two offspring groups comparable for blood pressure and estimated protein intake. This careful selection may have avoided the interference of several confounding factors. Even so the possibility that renal biopsy could have revealed a non-diabetic renal disease cannot be ruled out, though it seems unlikely given the negative results of the non-invasive procedures.

It has been hypothesized that microalbuminuria is a feature of the insulin-resistance syndrome in the general population on the basis of its association with impaired glucose tolerance, hyperinsulinaemia, hypertension, and dyslipidaemia [9-11]. However, we did not find any metabolic abnormalities in our A-off group, which also showed normal OGTT and normal insulin values, indicating that their increased AER was not due to a recognizable prediabetic state. It is possible that the exclusion of subjects with impaired glucose tolerance, NIDDM or hypertension in offspring selection may have resulted in a sample free of syndrome $X$.

The difference in AER between the two offspring groups, although statistically significant, is indeed slight and could be merely due to chance. However, our result is strengthened by the fact that, in stepwise multiple regression analysis, parental AER was the most potent independent regressor of offspring AER. This relationship suggests that an inherited unknown factor may be implicated in the increased transglomerular passage of albumin in the A-off group, and is in line with previous studies on diabetic and non-diabetic populations. In diabetic patients, nephropathy occurs only in a subset of subjects and clusters in families [5], and in non-diabetic subjects microalbuminuria occurs more frequently in the presence of parental history of diabetes [11]. Furthermore, our present findings are consistent with the postulate that genetic factors play a part in determining susceptibility to diabetic nephropathy, and that this predisposition is inherited independently of diabetes, but expressed only in those who develop the disease [5]. Nevertheless, the possibility that albuminuria due to non-diabetic causes escaped our selection and was the reason for the difference between the two groups cannot be completely excluded.

Systolic blood pressure was the other independent variable that helped to explain offspring AER variance, suggesting that it influences glomerular permeability to albumin, even if it is in the normal range. Its role as determinant of AER has been reported for diabetic and non-diabetic subjects. Furthermore, in Pima Indians it has been demonstrated that prediabetic blood pressure predicts abnormal AER after the onset of diabetes [7].

In conclusion, this study demonstrates that AER is increased in non-diabetic offspring of NIDDM patients with nephropathy, and that offspring AER is 
mainly related to parent AER. Further investigations are needed to clarify the nature of inherited factors involved in the susceptibility to diabetic nephropathy.

\section{References}

1. Mogensen CE (1984) Microalbuminuria predicts clinical proteinuria and early mortality in maturity-onset diabetes. N Engl J Med 310: 356 -360

2. Nelson RG, Pettitt DJ, Carrahar MJ, Baird HR, Knowler WC (1988) Effect of proteinuria on mortality in NIDDM. Diabetes 37: 1499- 1504

3. Jarrett RJ, Viberti GC, Argyropoulos A, Hill RD, Mahmud U, Murrells TJ (1984) Microalbuminuria predicts mortality in non-insulin-dependent diabetes mellitus. Diabet Med 1: 17-19

4. Krolewski AS, Canessa M, Warram JH et al. (1988) Predisposition to hypertension and susceptibility to renal disease in insulin-dependent diabetes mellitus. N Engl J Med 318: $140-145$

5. Seaquist ER, Goetz FC, Rich S, Barbosa J (1989) Familial clustering of diabetic kidney disease. N Engl J Med 320: 1161-1165

6. Viberti GC, Keen H, Wiseman MJ (1987) Raised arterial pressure in parents of proteinuric insulin dependent diabetics. BMJ 295: 515-517

7. Nelson RG, Pettitt DJ, Baird HR et al. (1993) Pre-diabetic blood pressure predicts urinary albumin excretion after the onset of type 2 (non-insulin-dependent) diabetes mellitus in Pima Indians. Diabetologia 36: 998-1001

8. Pettitt DJ, Saad MF, Bennett PH, Nelson RG, Knowler WC (1990) Familial predisposition to renal disease in two generations of Pima Indians with type 2 (non-insulin-dependent) diabetes mellitus. Diabetologia 33: 438-443
9. Nelson RG, Runzelman CL, Pettitt DJ, Saad MF, Bennett PH, Knowler WC (1989) Albuminuria in type 2 (non-insulin-dependent) diabetes mellitus and impaired glucose tolerance in Pima Indians. Diabetologia 32: 870-876

10. Haffner SM, Stern MP, Gruber MK, Mitchell BD, Patterson JK (1990) Microalbuminuria, potential marker for increased cardiovascular risk factor in non-diabetic subjects? Arteriosclerosis 10: 727-731

11. Haffner SM, Gonzales C, Valdez RA et al. (1993) Is microalbuminuria part of the prediabetic state? The Mexico City Diabetes Study. Diabetologia 36: 1002-1006

12. Bogardus C, Lillioja S, Foley J et al. (1987) Insulin resistance predicts the development of non-insulin dependent diabetes mellitus in Pima Indians. Diabetes 36 [Suppl 1]: 47A (Abstract)

13. Haffner SM, Stern MP, Hazuda HP, Mitchell BD, Patterson JK (1988) Increased insulin concentrations in non-diabetic offspring of diabetic parents. N Engl J Med 319: 1297-1301.

14. World Health Organisation (1985) Diabetes Mellitus. Report of a WHO Study Group. Geneva (Technical Report Service Number 727)

15. World Health Organisation WHO (1978) Arterial hypertension: report of a WHO expert Committee. Geneva. Tech Rep Ser No 628

16. Maroni BJ, Steinman TI, Mitch WE (1985) A method for estimating nitrogen intake of patients with chronic renal failure. Kidney Int 27: 58 -65

17. Friedewald WT, Levy RI, Fredricison DS (1972) Estimation of the concentration of low density lipoprotein cholesterol in plasma without use of the preparative ultracentrifuge. Clin Chem 18: 499-502

18. SAS/STAT (1988) User's Guide Release 6.03 Edition. SAS Institute, Cary, $\mathrm{NC}$

19. Ritz E, Hasslacher C, Tschope W (1990) Diabetic nephropathy - are there differences between type I and type II. Miner Electrolyte Metab 16: 69-72 